\title{
Aspectos socioeconômicos dos genitores de crianças com microcefalia relacionada ao Zika Vírus
}

\author{
Socioeconomic aspects of genitors of children with \\ microcefalia related to Zika Virus
}

\author{
'Amanda Estrela Gonçalves, ${ }^{2}$ Sibele Dayane Brazil Tenório, ${ }^{3}$ Priscila Correia da Silva Ferraz \\ 'Autora para correspondência. Faculdade de Tecnologia e Ciências. Salvador, Bahia, Brasil. \\ ORCID 0000-0001-6800-4356. amandagoncalves55@hotmail.com \\ ${ }^{2}$ Faculdade de Tecnologia e Ciências. Salvador, Bahia, Brasil. ORCID 0000-0003-1 195-8460. belly-brazil@hotmail.com \\ ${ }^{3}$ Faculdade de Tecnologia e Ciências. Salvador, Bahia, Brasil. ORCID 0000-0001-8695-6289.pris_correia@hotmail.com
}

RESUMO | INTRODUÇÃO: A microcefalia é uma má formação cerebral que não tem cura e é caracterizada por um perímetro cefálico inferior ao esperado para idade e sexo. É relacionada ao Zika Vírus que é transmitido pelo mosquito Aedes e quando contraído nos primeiros meses gestacionais aumentam as chances do feto desenvolver a microcefalia, já que o desenvolvimento cerebral tem início na fase intra-uterina. OBJETIVO: Esta pesquisa tem como objetivo caracterizar o perfil socioeconômico dos responsáveis por criança com diagnóstico de microcefalia relacionado ao Zika vírus. MÉTODOS: Foram entrevistados 41 cuidadores principais das crianças com microcefalia em Salvador e Região Metropolitana de Salvador, através de um questionário contendo 30 perguntas fechadas que abordavam questões familiares, socioeconômicas e sanitárias. RESULTADOS: Observou-se que a maioria dos bebês tinha entre 15-18 meses e tiveram seu diagnóstico em sua maior parte no momento intrauterino. Houve uma frequência elevada de desemprego entre os pais, que relataram sobreviver com até 1 salário mínimo mensal, possuíam ensino médio completo, encontravam-se solteiros ou em união estável e um número significativo citaram condições sanitárias desfavoráveis e negaram usar repelente. De um modo geral, os principais cuidadores relataram que não possuíam residência própria e grande parte levavam as crianças para fazerem atendimentos multiprofissionais tanto em hospitais públicos como em instituições sem fins lucrativos. CONCLUSÃO: Há uma frequência predominante de genitores que dispõem de crianças com microcefalia relacionada ao Zika vírus em baixas condições socioeconômica, que consequentemente não conseguem suprir a maioria das necessidades que um lactente com má formação necessita.
ABSTRACT | INTRODUCTION: Microcephaly is a poor cerebral formation that has no cure and is characterized by a cephalic perimeter lower than expected for age and sex. It is related to the Zika virus that is transmitted by the mosquito Aedes and when contracted in the first gestational months increase the chances of the fetus to develop microcephaly, since the cerebral development begins in the intrauterine phase. OBJECTIVE: This study aims to characterize the socioeconomic profile of those responsible for children with a diagnosis of microcephaly related to Zika virus. METHODS: We interviewed 41 primary caregivers of children with microcephaly in Salvador and Metropolitan Region of Salvador, through a questionnaire containing 30 closed questions that addressed family, socioeconomic and health issues. RESULTS: It was observed that most of the babies were between 15-18 months and had their diagnosis mostly intrauterine. There was a high frequency of unemployment among parents, who reported surviving up to 1 monthly minimum wage, had completed high school, were single or in a stable union and a significant number cited unfavorable health conditions and denied using repellent. Overall, the primary caregivers reported that they did not have their own residence, and most of them took the children to multiprofessional care in both public hospitals and non-profit institutions. CONCLUSION: There is a predominant frequency of parents who have children with Zeca virus-related microcephaly in low socioeconomic conditions, who consequently fail to meet most of the needs that a malnourished infant needs.

KEYWORDS: Socioeconomic. Microcephaly. Zika. Primary caregiver.

PALAVRAS-CHAVE: Socioeconômico. Microcefalia. Zika. Principal cuidador. 


\section{Introdução}

O Zika é um vírus transmitido pelo mosquito Aedes aegypti, que foi apontado pela primeira vez no Brasil em abril de 2015. Na apresentação do quadro clínico os sintomas mais prevalentes são cefaléia, febre baixa, dores leves nas articulações, manchas vermelhas na pele, coceira e vermelhidão nos olhos, porém ocorreram casos em que as pessoas infectadas não desenvolveram manifestações clínicas. Fatores ambientais influenciam a propagação desses vetores e facilitam desta forma um risco maior de contaminação para a população que reside em locais com esgoto a céu aberto, água acumulada em recipientes, e falta de saneamento básico'.

A grave epidemia da microcefalia chama a atenção para a necessidade urgente de grandes investimentos voltados à melhoria das condições de vida das populações urbanas no Brasil. Se, por um lado, a falta de água nas moradias faz com que seja necessário o armazenamento doméstico, criando-se locais propícios para a reprodução do mosquito, por outro lado, as chuvas favorecem o acúmulo de água em moradias precárias ou onde há resíduos depositados, gerando ambientes favoráveis à proliferação do vetor. A implantação massiva da coleta seletiva de resíduos sólidos, com a separação e destino adequado para os resíduos recicláveis, é uma medida importante não somente para o controle vetorial, mas também sob a perspectiva ambiental. Os esgotos a céu aberto, onde também se encontra lixo depositado, são outra fonte inesgotável de criadouros para o Aedes aegypti além de outros vetores e precisam ser eliminados ${ }^{2}$.

A microcefalia não é uma patologia recente, porém era de caráter raro, caracterizada por uma malformação congênita em que o cérebro não evolui da forma apropriada. O perímetro cefálico da criança é relativamente menor que o padrão estabelecido para a normalidade esperada pelo sexo e idade, que é de $31,9 \mathrm{~cm}$ para meninos e $31,5 \mathrm{~cm}$ para meninas, dados atualizados de acordo com os casos de microcefalia por vírus Zika ${ }^{3}$.

A microcefalia fragmenta-se em dois grupos principais: microcefalia primária (genética) que ocorre situações em que o cérebro é pequeno e não completou o seu desenvolvimento embrionário normal devido a fatores genéticos, cromossômicos e malformações, ou, pelo efeito das condições ambientais no útero, os bebês são distinguidos logo ao nascerem devido ao baixo perímetro cefálico. Já na secundária implica que o cérebro está completo para o desenvolvimento embrionário normal, mas, em seguida, sofre uma lesão difusa e altera o seu crescimento evolutivo típico, em especifico nos primeiros dois anos de vida ${ }^{4,5}$.

Infecções através do vírus Zika, que ocorrem durante o primeiro trimestre gestacional, têm o mais profundo impacto sobre o desenvolvimento do feto e, muitas vezes ameaçam a sua viabilidade. Elas podem afetar a proliferação e diferenciação celular, - que conduz a malformações do órgão e limitação do crescimento. $O$ mecanismo pelo qual o vírus Zika pode causar microcefalia fetal é desconhecido, embora estudos indiquem que o vírus Zika é capaz de evadir as respostas imunoprotetoras normais da placenta. Outra possibilidade é que o vírus tem propriedades neurotrópicas e, através da placenta, está a aceder diretamente e danificar o cérebro em desenvolvimento ${ }^{6,7}$.

Os Determinantes Sociais da Saúde são as condições sociais que os indivíduos vivenciam, composto pelos aspectos econômicos, culturais, étnicos/raciais, psicológicos e comportamentais que influenciam a incidência de problemas de saúde e seus fatores de risco na população. A epidemia de Zika que se espalha por boa parte do país, propagada pelo mosquito Aedes aegypti, parece estar diretamente ligada a esses determinantes ${ }^{8}$.

Esta pesquisa aponta para a percepção das características sociais e econômicas que esses genitores vivenciam, impactando na necessidade de tornar as políticas públicas mais direcionadas a essa população. Esse estudo tem como objetivo caracterizar o perfil socioeconômico dos responsáveis por criança com diagnóstico de microcefalia relacionado ao Zika Vírus, além da identificação das condições sanitárias.

\section{Material e Métodos}

Trata-se de um estudo transversal, quantitativo, tendo como população os responsáveis legais de crian- 
ças com diagnóstico de Microcefalia, nascidas no estado da Bahia, e cadastradas no projeto Abraço a Microcefalia, com sede em Salvador, Bahia. $O$ Projeto Abraço a Microcefalia que tem como intuito oferecer orientação, acolhimento, apoio e suporte às famílias de crianças com diagnóstico de Microcefalia, através de oficinas, palestras, doações e atendimento, de forma voluntária e gratuita.

Após a aprovação do projeto pelo Comitê de Ética em Pesquisa do Instituto Mantenedor do Ensino Superior (IMES), o mesmo foi apresentado à gestão e, após consentimento, a amostra foi selecionada, não probabilística por conveniência, composta por 49 genitores, que assinaram o Termo de Consentimento Livre e Esclarecido (TCLE), confirmando a participação no estudo. Foram excluídos do estudo responsáveis legais com comprometimentos neurológicos, linguísticos ou que se recusassem assinar o referido TCLE totalizando 8 responsáveis. Ao final, a amostra do estudo foi composta por 41 responsáveis legais de crianças com diagnóstico de Microcefalia pós Zika vírus.

Foi realizado um estudo piloto para calibração do instrumento de coleta, em outubro de 2016, com 2 genitoras de crianças com diagnóstico de Microcefalia, sendo necessárias alterações do questionário para maiores esclarecimentos em algumas perguntas.

A abordagem aos responsáveis era efetuada no ambiente físico do Projeto Abraço a Microcefalia, enquanto os mesmos encontravam-se na sala de espera, aguardando algum dos atendimentos multiprofissionais, seguida de uma prévia apresentação do entrevistador e informação sobro objetivo da pesquisa.

Os dados foram coletados por meio de entrevista, através de um questionário estruturado, elaborado pelas autoras, composto por 30 questões objetivas abordando condições familiares, socioeconômicas e sanitárias, o que possibilitou uma maior exposição de dados, com duração aproximada de 10 minutos para cada entrevista. Foram respeitadas a individualidade dos responsáveis legais, sendo aplicadas individualmente, em uma sala reservada, no ambiente físico do Projeto Abraço a Microcefalia. O período de coleta aconteceu entre os meses de Fevereiro e Março de 2017.
O banco de dados foi criado no Microsoft Excel 2013, sistematizado no software SPSS (versão 22.0) e realizada uma análise estatística descritiva (frequência absoluta e relativa) com a finalidade de identificar as características gerais e específicas da amostra estudada. Os resultados obtidos foram apresentados na forma de tabelas comparativas formuladas no Microsoft Excel 2013. Sendo submetido ao Comitê de Ética em Pesquisa do Instituto Mantenedor do Ensino Superior, obtendo aprovação em Outubro/2016, com CAAE 57341916.0.0000.5032.

\section{Resultados e Discussão}

A amostra participante desse estudo foi composta por 41 cuidadores principais de crianças com diagnóstico de microcefalia pós Zika vírus. Sendo $53,66 \%$, das crianças do sexo feminino, e $46,34 \%$ do masculino. Correlacionando com outros estudos", $58 \%$ crianças eram do sexo feminino e $41 \%$ do masculino; e observou-se também que Xavier et al. (2014) relatam em sua pesquisa possuir 20 meninos e 19 meninas, fica demonstrado que não há predominância de gênero especifico, para o diagnóstico da microcefalia, sendo confirmado em estudos ${ }^{11}$, que mostram que não há domínio de sexo sobre o diagnóstico de Paralisia Cerebral (PC) (Tabela 1).

A maior parte das crianças, nesse estudo, possuiam faixa etária com amplitude de 14 meses, mínimo de 9 meses e máximo de 23 meses, com uma prevalência maior entre a faixa etária de 15-18 meses $(75,60 \%)$, ou seja, nasceram entre Out/2015 a Jan/2016, evidenciando a relação da Zika com a microcefalia, já que a epidemia do vírus também foi dada na mesma época. $O$ Brasil confirmou em outubro de 2015 um aumento atípico dos casos de microcefalia em Pernambuco e, outros estados do nordeste também confirmaram um pico de nascimento desde outubro de 2015. O número de casos de microcefalia neonatal, possivelmente relacionados ao vírus Zika, cresceu significativamente no Brasil, incluindo casos detectados em aproximadamente 724 municípios do país ${ }^{10,11,12}$.

A cor de pele predominante foi a parda, em que $56,10 \%$ dos responsáveis declararam esta etnia para suas crianças, $31,70 \%$ negros e $12,20 \%$ bran- 
cos (Tabela 1), corroborando com um estudol $1 \mathrm{em}$ $P C$, que relata $76,9 \%$ cor parda e $23,1 \%$ negro. O Instituto Brasileiro de Geografia e Estatística (IBGE) cita, no último censo demográfico, que a Bahia possui maior parte da sua população de cor parda $(59 \%)$, colaborando para o índice das pesquisas em geral no estado.

O diagnóstico da microcefalia foi dado a $53,66 \%$ no período pré-natal, 34,14\% peri-natal e 12,20\% no pós-natal, correlacionando com outra pesquisa13 que cita o descobrimento da má formação cerebral em aproximadamente $70 \%$ no momento intrauterino, podendo associar que o pré-natal é fundamental para o conhecimento do diagnóstico ainda na gravidez, preparando a mãe, a família e o ambiente para a chegada de uma criança que precisará de diversos cuidados e gastos necessários, dando também essa conclusão baseando-se nas evidências de estudos ${ }^{9}$ em que a identificação da microcefalia é 2,6 vezes maior no momento do nascimento para mães que não realizaram todos os pré-natais (Tabela 1 ).

No acompanhamento do pré-natal, a identificação precoce da circunferência craniana menor pode dar maior êxito sobre a etiologia da microcefalia, as- sim como, preparar melhor a mãe e os familiares para o nascimento de um bebê com má formação. É importante ressaltar que o diagnóstico precoce, a notificação e o registro adequado são essenciais para a investigação sobre a microcefalia relacionada ao Zika vírus. A polinésia Francesa desde 2013 enfrenta o maior surto de infecção por vírus Zika com possível transmissão perinatal, seja via transplacentária, durante o parto, amamentação ou contato direto com a mãe, porém, o número de infecções em RN foi subestimado certamente pela falta de diagnóstico e acompanhamento ${ }^{14}$.

De acordo com pesquisas realizadas $9,10,11,12,13,14,15$, constataram-se que $50 \%$ e $71 \%$ das mães, respectivamente, realizaram 6 ou mais pré-natais. $E$, em outra pesquisa $^{10}$, relata que todas as genitoras fizeram pelo menos 1 consulta, assim como no presente estudo, em que a realização completa do pré-natal foi feita pela maior parte das mães $(87,80 \%)$. As outras remanescentes $(12,20 \%)$ não efetuaram pelo menos uma das consultas necessárias por diversos motivos, como descoberta tardia da gestação $(n=3)$, internamento hospitalar $(n=1)$, impossibilitando a ida ao atendimento e não comparecimento as consultas $(n=1)$, deixando claro a falta de informação sobre a importância de um planejamento familiar (Tabela 1)

Tabela 1. Identificação das crianças com microcefalia relacionado ao zika vírus e do cuidador principal ( $\mathrm{n}=41$ ), em Salvador e região metropolitana.

\begin{tabular}{|c|c|c|c|c|c|}
\hline \multirow{2}{*}{ CRIANÇA } & & & \multirow{2}{*}{ PRINCIPAL CUIDADOR } & \multirow[b]{2}{*}{$f$} & \multirow[b]{2}{*}{$\%$} \\
\hline & $\mathbf{F}$ & $\%$ & & & \\
\hline Gênero & & & Parentesco com a criança & & \\
\hline Masculino & 19 & 46,34 & Pai & 8 & 19,51 \\
\hline Feminino & 22 & 53,66 & Mãe & 33 & 80,49 \\
\hline Faixa etária & & & Estado civil & & \\
\hline $9-12$ meses & 1 & 2,44 & Solteiro & 29 & 70,73 \\
\hline $12-15$ meses & 3 & 7,32 & Casado & 11 & 26,83 \\
\hline $15-18$ meses & 31 & 75,60 & Divorciado & 1 & 2,44 \\
\hline $18-21$ meses & 4 & 9,76 & Viúvo & 0 & 0,00 \\
\hline $21-23$ meses & 2 & 4,88 & $\begin{array}{l}\text { Convive com o genitor(a) } \\
\text { da criança }\end{array}$ & & \\
\hline Cor de pele & & & Sim & 26 & 63,41 \\
\hline Branco & 5 & 12,20 & Não & 15 & 36,59 \\
\hline Negro & 13 & 31,70 & Realização de pré-natal & & \\
\hline Pardo & 23 & 56,10 & Sim & 36 & 87,80 \\
\hline Diagnóstico da Microcefalia & & & Não & 5 & 12,20 \\
\hline Pré-natal & 22 & 53,66 & & & \\
\hline Peri-natal & 14 & 34,14 & & & \\
\hline Pós-natal & 5 & 12,20 & & & \\
\hline
\end{tabular}

f - frequência absoluta; \% - frequência relativa Fonte: Elaborado pelas autoras, 2017. 
A entrevista foi respondida pelos principais responsáveis, sendo 8 pais $(19,51 \%)$ e 33 mães $(80,49 \%)$, correlacionando com estudo de crianças com necessidades especiais ${ }^{16}$, confirmando que a cuidadora primária é a mãe em $92 \%$ dos casos. $O$ estado civil predominou-se em $70,73 \%$ solteiros e no geral, $63,41 \%$ convive com $\circ$ (a) genitor (a) da criança, concordando com outro autor ${ }^{9}$ em que $72 \%$ da amostra declararam ser solteiras ou viver em uma união estável, o que demonstra que ainda há um número significativo de crianças que são recebidas apenas pela mãe e não tem a presença do pai todos os dias para o acompanhamento necessário e poder dividir as tarefas que sobrecarregam a genitora desses bebês (Tabela 1).

O atendimento multiprofissional foi empreendido por todas as crianças participantes, considerando que todas realizam atendimento em mais de um local, simultaneamente. O Hospital Sarah Kubistcheck Salvador caracterizou o mais predominante, realizando atendimento em $60,97 \%$ da amostra, algumas são mais assistidas pela quantidade de especialistas que frequentam, mas todas têm em comum os atendimentos ocorridos em Hospitais públicos e
Instituições sem fins lucrativos, definindo assim uma questão econômica irregular, com dependências de políticas públicas e trabalhos voluntários para atenção à saúde e desenvolvimento de seus bebês. Observou-se que, os atendimentos realizados pela criança com microcefalia são $85,6 \%$ SUS e $15,4 \%$ particular, desta forma confirmando os dados da presente pesquisa sobre o uso da assistência públi$\mathrm{ca}^{17}$ (Gráfico 1).

Todos os locais citados foram: Centro de Prevenção e Reabilitação do Portador de Deficiência (CEPRED) (48,78\%), Hospital Sarah Salvador $(60,97 \%)$, Núcleo de Atendimento a Criança com Paralisia Cerebral (NACPC) (4,88\%),Associação dos Pais e Amigos dos Excepcionais (APAE) (7,32\%), Abraço a Microcefalia (AMA) $(46,34 \%)$, Instituto dos Cegos da Bahia $(34,14 \%)$, Hospital Roberto Santos (36,59\%), Hospital Irmã Dulce $(31,7 \%)$, Clinica Escolas $(9,76 \%)$, Clinicas particulares (14,63\%) e outros locais (12,2\%), como: Maternidade Climério de Oliveira (MCO), Instituto de Organização Neurológico da Bahia (ION), Hospital Martagão Gesteira, Centro Social Marta Alencar e Centro Pestalozzi de Reabilitação (Gráfico 1).

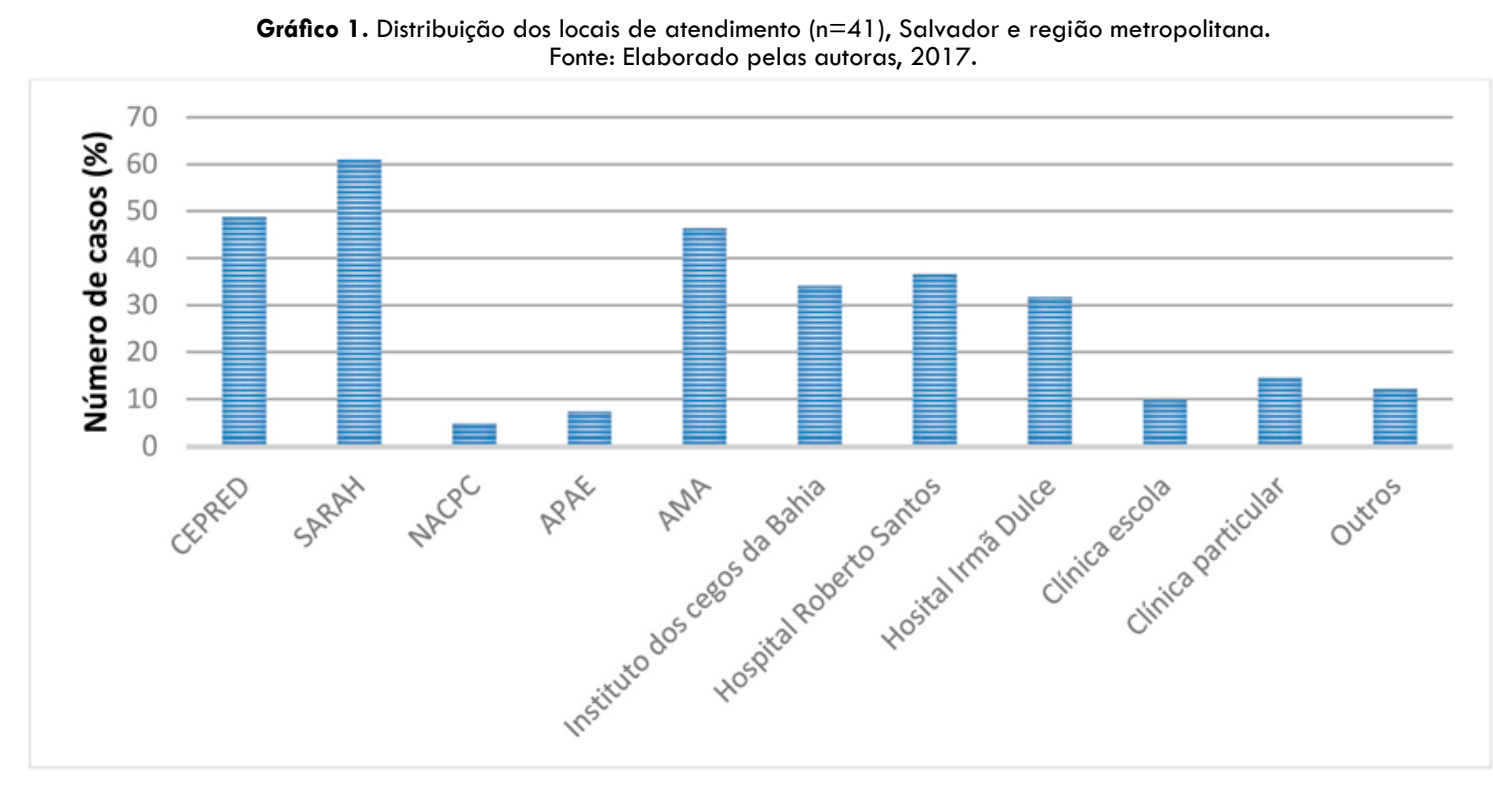


Referente aos dados sociais dos genitores (Tabela 2 ), o nível de prevalência paterna foi maior entre a faixa etária de $35-45$ anos $(34,14 \%), 39,02 \%$ deles possuem ensino médio completo, $58,54 \%$ estão empregados, e $34,14 \%$ recebem mensalmente até 1 salário mínimo. Dados esses que traçam uma condição estável para a maioria, mas não deixam de ter grandes incidência de desempregos $(34,04 \%)$ e sem nenhuma renda mensal $(24,39 \%)$, quadro preocupante devido ao comprometimento diário dos gastos com tratamento multiprofissional da criança com microcefalia. Segundo traz o estudo em PC1 1, 46,2\% dos pais tem grau de escolaridade fundamental incompleto, contrariando aos dados coletados na presente pesquisa, entretanto, sobre as demais variáveis paternas, não foram encontrados estudos correspondentes de outros autores para discussão.

Quanto às características maternas, observou-se a prevalência na faixa etária entre 25-35 anos $(34,14 \%)$, já os autores ${ }^{13,14,15}$ trazem a idade média de 24 e 27 anos respectivamente, enquanto Vargas et al. (2016) diz que $73 \%$ das mães tem até 29 anos, traçando um perfil dessas genitoras, com idade superior a 25 anos. A escolaridade delas no presente estudo prevaleceu com ensino médio completo $(41,46 \%)$, demostrando que a sua maioria também possui ensino médio $(55,5 \%)^{15}$. A escolaridade da mãe reflete as condições socioeconômicas e está as- sociada a um maior risco de morte neonatal, onde aponta a escolaridade materna como fator de risco importante para a sobrevivência infantil e indicador da condição socioeconômica ${ }^{18}$ (Tabela 2).

A profissão das genitoras caracterizou-se em donas do lar $(43,90 \%)$ e desempregadas $(31,71 \%)$, possuindo renda mensal de até 1 salário mínimo $(65,85 \%)$ (Tabela 2). Há relatos de que muitas deixaram de trabalhar ou realizar outras atividades remuneradas para cuidar dos seus bebês. Também observaram em uma pesquisa com total de 40 participantes, que a maior parte delas $(n=16)$ são ocupadas do lar, demonstrando que esse tipo de má formação necessita de mais atenção de suas genitoras, pois crianças com comprometimento neurológico dependem de um cuidador para realizar atividades de vida diária, uma tarefa complexa que requer tempo, fazendo com que consequentemente as mães abdiquem seus empregos ${ }^{10,19}$.

Segundo Xavier et al. (2014), o que pode aumentar a probabilidade de déficits no desenvolvimento motor, é o nível socioeconômico da família. Algumas pesquisas evidenciaram a importância dos fatores socioeconômicos na determinação da saúde da criança e considera-se a educação da mãe e a renda familiar como elementos básicos, por serem indicadores de recursos disponíveis e conhecimento ou comportamento em relação à saúde da criança.

Tabela 2. Dados sociais de genitores das crianças com microcefalia relacionada ao zika vírus $(n=41)$, em Salvador e região metropolitana.

\begin{tabular}{|l|c|c|l|l|c|}
\hline \multicolumn{2}{|c|}{ PAI } & \multicolumn{2}{c|}{ MÃE } & \multicolumn{2}{c|}{} \\
\cline { 2 - 5 } & F & $\%$ & & f & $\%$ \\
\hline Escolaridade & & & Escolaridade & & \\
\hline Primário completo & 1 & 2,44 & Primário completo & 0 & 0,00 \\
\hline Primário incompleto & 0 & 0,00 & Primário incompleto & 6 & 14,63 \\
\hline Fundamental completo & 0 & 0,00 & Fundamental completo & 0 & 0,00 \\
\hline Fundamental incompleto & 7 & 17,07 & Fundamental incompleto & 4 & 9,76 \\
\hline Médio completo & 16 & 39,02 & Médio completo & 17 & 41,46 \\
\hline Médio incompleto & 10 & 24,39 & Médio incompleto & 11 & 26,83 \\
\hline Superior completo & 4 & 9,76 & Superior completo & 2 & 4,88 \\
\hline Superior incompleto & 3 & 7,32 & Superior incompleto & 1 & 2,44 \\
\hline
\end{tabular}


Tabela 2. Dados sociais de genitores das crianças com microcefalia relacionada ao zika vírus ( $n=41$ ), em Salvador e região metropolitana. (continuação)

\begin{tabular}{|c|c|c|c|c|c|}
\hline \multirow{2}{*}{ PAI } & \multirow[b]{2}{*}{$\mathbf{F}$} & \multirow[b]{2}{*}{$\%$} & \multirow{2}{*}{ MÃE } & \multirow[b]{2}{*}{$\mathbf{f}$} & \multirow[b]{2}{*}{$\%$} \\
\hline & & & & & \\
\hline Faixa etária & & & Faixa etária & & \\
\hline $15-25$ anos & 10 & 24,39 & 15-25 anos & 13 & 31,71 \\
\hline $25-35$ anos & 12 & 29,27 & 25-35 anos & 14 & 34,14 \\
\hline $35-45$ anos & 14 & 34,14 & $35-45$ anos & 13 & 31,71 \\
\hline $45-55$ anos & 5 & 12,20 & 45-55 anos & 1 & 2,44 \\
\hline Profissão & & & Profissão & & \\
\hline Desempregado & 14 & 34,14 & Desempregado & 13 & 31,71 \\
\hline Autonomo & 3 & 7,32 & Autonomo & 0 & 0,00 \\
\hline Empregado & 24 & 58,54 & Empregado & 6 & 14,63 \\
\hline Do lar & 0 & 0,00 & Do lar & 18 & 43,90 \\
\hline Estudante & 0 & 0,00 & Estudante & 4 & 9,76 \\
\hline Renda & & & Renda & & \\
\hline Até 1 salário mínimo & 14 & 34,14 & Até 1 salário mínimo & 27 & 65,85 \\
\hline Entre 1 e 2 salários mínimos & 7 & 17,07 & Entre 1 e 2 salários mínimos & 3 & 7,32 \\
\hline Entre 2 e 3 salários mínimos & 2 & 4,88 & Entre 2 e 3 salários mínimos & 1 & 2,44 \\
\hline Acima de 3 salários mínimos & 1 & 2,44 & Acima de 3 salários mínimos & 0 & 0,00 \\
\hline Não sabe informar & 5 & 12,20 & Não sabe informar & 0 & 0,00 \\
\hline Não participa financeiramente & 2 & 4,88 & Não participa financeiramente & 0 & 0,00 \\
\hline Não possui renda & 10 & 24,39 & Não possui renda & 10 & 24,39 \\
\hline
\end{tabular}

f - frequência absoluta; \% - frequência relativa

Fonte: Elaborado pelas autoras, 2017.

Em relação às condições sócio demográficas (Tabela 3 ), dessas 41 famílias, 90,24\% vivem em zona urbana e $41,46 \%$ têm seu próprio imóvel, entretanto foi observado que um grande número de famílias que alegaram morar de aluguel ou de favor em casa de amigos/familiares, um somatório de $58,64 \%$, sendo assim a maioria não possui sua própria residência.

Apesar de não encontrar estudos que tragam essas variáveis abordando a microcefalia, descreve-se sobre $\mathrm{PC}^{20}$ e traz que o somatório dos seus achados também demonstram que moradia alugada ou cedida é o que prevalece, então, pode-se concluir que a maioria das famílias não estão preparadas financeiramente para uma vida estável com essas crianças, que às vezes sofrem com mudanças de ambientes e acabam tendo que se adaptar para uma nova morada, podendo até apresentar mais riscos a saúde do bebê e seus genitores a depender das condições sanitárias que seu novo entorno apresente.
Na sua maioria, 90,24\% dessas residências possuem mais de 4 cômodos e as crianças convivem no mesmo lar com mais 3 pessoas $(43,90 \%)$, mais predominantemente, entre mães $(100 \%)$, pais $(63,41 \%)$ e irmãos $(58,54 \%)$ já que $56,10 \%$ afirmaram ter outros filhos, o que aumenta muito mais - trabalho dessas mães, que precisam cuidar da criança com deficiência e ainda de outros filhos que são em maior parte ainda crianças, correlacionando com várias pesquisas ${ }^{21,22}$ estudo de crianças com doenças crônicas, descreve que a maioria das mães tem pelo menos mais 1 filho e o estudo em $\mathrm{PC}^{11}$, traz que a quantidade de pessoas morando na casa é de $61,5 \%$ até 4 habitantes e $38,5 \%$ acima de 5 moradores (Tabela 3). $O$ outro morador mais comum são os pais, que segundo a pesquisa a maioria trabalham e consequentemente deixam a mãe sozinha maior parte do tempo para cuidar do(a) deficiente, segundo Salvador (2013) no estudo de crianças com doenças crônicas, a maioria dos pais trabalham 
e apresenta-se como o principal provedor da renda familiar. Entre essas pessoas que coabitam 53,66\% além da mãe tiveram Zika, uma confirmação de que - local possui grandes fatores de risco para a contaminação e que os cuidados para prevenção não aconteceram ou foram ineficazes, entretanto, sobre as demais variáveis não foram encontrados estudos correspondentes de outros autores para discussão.

As crianças com microcefalia relacionada ao Zika em sua maior parte $(63,41 \%)$ recebem o benefício assistencial do Instituto Nacional do Seguro Social (INSS), corroborando com outra pesquisa em $\mathrm{PC}^{11}$, que situa $92,3 \%$ das crianças possuem esta assistência. $O$ beneficio é a garantia de um salário-mínimo mensal à pessoa com deficiência e ao idoso com 65 anos ou mais que comprovem não ter condições de manter a própria manutenção nem de tê-la provida por sua família ${ }^{23}$ (Tabela 3).

Foi legalizada a lei que garante 0 direito ao benefício de prestação continuada (BPC) temporário previsto na Lei $13.301 / 2016$ no valor de 1 salário-mínimo mensal, pelo período máximo de 3 anos, na condição da criança vítima de microcefalia oriunda de doenças transmitidas pelo Aedes Aegypti. Também ficou determinado que a licença-maternidade prevista na Consolidação das Leis do Trabalho (CLT) será de 180 dias no caso das mães de crianças acometidas por sequelas neurológicas relacionada ao mosquito Aedes ${ }^{24}$.

Pode-se concluir que a renda das genitoras são a base desse auxílio, já que $65,85 \%$ disseram receber até um salário mínimo e $75,61 \%$ equivale ao somatório de Dona do lar e desempregadas, logo, aquelas que ainda não recebem esse beneficio $(36,59 \%)$ estão provavelmente vivendo de maneira mais dificultosa, dependendo da ajuda dos familiares e amigos, contudo mostra de forma mais detaIhada, citando valores, uma mediana da renda per capita familiar de $400 \$ 10$ (Tabela 3 ).
Relacionado a coleta de lixo, os dados mostram um bom indicie, $60,97 \%$ dizem haver a coleta mais de $3 x$ na semana, segundo Henriques et al (2016), a transmissão do vírus pelo mosquito Aedes ocorre com mais prevalência onde a coleta de lixo e condições sanitárias são reduzidas, seja na própria residência e/ou em seu entorno, condições essas, favoráveis para a sua proliferação sendo mais difícil - combate desses criadouros de mosquitos. Já nas condições sanitárias apesar de 68,29\%negarem haver esgoto a céu aberto próximo onde moram, $31,71 \%$ dizem o contrário e $56,10 \%$ confessaram não utilizar o repelente, um conjunto de fatores favoráveis para a proliferação do Aedes e infecção pelo Zika, sendo que $53,66 \%$ afirmaram que outras pessoas da casa contraíram o vírus (Tabela 3 ).

O IBGE traz dados de que $44 \%$ da população não tem esgotamento sanitário, segundo Reis (2015), o que identifica moradias inadequadas a saúde da população, um direito humano essencial. Além disso Abreu et al. (2016), relatam que quanto mais baixos os recursos econômicos e o grau de escolaridade, menor o saneamento básico e mais desfavorável as condições ambientais.

O transporte que predomina a ida a esses atendimentos é o ônibus $(82,93 \%)$ e aquelas que usam carro $(17,07 \%)$, algumas alegaram que ainda assim o carro é da prefeitura. Apesar de não ter sido encontrado questões sobre transporte em estudos com Microcefalia, achou-se em PC que $50 \%$ de suas amostras não possuem veículo próprio, ou seja, 50\% utilizam transporte público para ir às consultas ${ }^{20}$. Sendo assim, fica claro que grandes partes das famílias não dispõem de conforto e segurança para transportar suas crianças, além de não garantir o cumprimento de horários dos atendimentos, retrato de uma questão econômica insatisfatória (Tabela 3). 
Tabela 3. Condições sociodemográficas das famílias de crianças com microcefalia relacionada ao zika vírus ( $\mathrm{n}=41$ ), em Salvador e região metropolitana.

\begin{tabular}{|c|c|c|c|c|c|}
\hline \multirow{2}{*}{ Variável } & & & \multirow{2}{*}{ Variável } & \multirow[b]{2}{*}{$f$} & \multirow[b]{2}{*}{$\%$} \\
\hline & $\mathbf{F}$ & $\%$ & & & \\
\hline Tipo de habitação & & & Outros filhos & & \\
\hline Urbana & 37 & 90,24 & Sim & 23 & 56,10 \\
\hline Rural & 4 & 9,76 & Não & 18 & 43,90 \\
\hline Condições de habitação & & & Benefício assisłencial & & \\
\hline Própria & 17 & 41,46 & Sim & 26 & 63,41 \\
\hline Alugada & 13 & 31,71 & Não & 15 & 36,59 \\
\hline Residencia de parente & 11 & 26,83 & Uso de repelente & & \\
\hline Comodos & & & Sim & 18 & 43,90 \\
\hline 1 cômodo & 2 & 4,88 & Não & 23 & 56,10 \\
\hline 2 cômodos & 0 & 0,00 & Condições sanitárias & & \\
\hline 3 cômodos & 2 & 4,88 & Sim & 28 & 68,29 \\
\hline 4 ou mais cômodos & 37 & 90,24 & Não & 13 & 31,71 \\
\hline $\begin{array}{l}\text { Número de pessoas que residem } \\
\text { junto á criança }\end{array}$ & & & Coleta de lixo & & \\
\hline 2 pessoas & 1 & 2,44 & $1 \times$ semana & 2 & 4,88 \\
\hline 3 pessoas & 18 & 43,90 & $2 x$ semana & 4 & 9,76 \\
\hline 4 pessoas & 13 & 31,71 & $3 x$ semana & 4 & 9,76 \\
\hline $5-6$ pessoas & 9 & 21,95 & Mais de $3 x$ semana & 25 & 60,97 \\
\hline Arranjo familiar & & & Não há coleta & 6 & 14,63 \\
\hline Pai & 26 & 63,41 & $\begin{array}{l}\text { Moradores da mesma casa } \\
\text { também tiveram zika }\end{array}$ & & \\
\hline Mãe & 41 & 100,00 & Sim & 22 & 53,66 \\
\hline Avós & 10 & 24,39 & Não & 19 & 46,34 \\
\hline Irmãos & 24 & 58,54 & Transporte predominante & & \\
\hline Tios & 8 & 19,51 & Ônibus & 34 & 82,83 \\
\hline Outros & 2 & 4,88 & Carro & 7 & 17,07 \\
\hline
\end{tabular}

$f$ - frequência absoluta; \% - frequência relativa

Fonte: Elaborado pelas autoras, 2017.

O atendimento multiprofissional é realizado por todas as crianças, a frequência da visita $1 \times$ na semana é maior para o Fonoaudiólogo $(68,29 \%)$ e Terapeuta Ocupacional (46,34\%), o Fisioterapeuta é procurado $2 x$ e $3 x$ na semana com mais frequência, por $56,01 \%$ e $17,07 \%$, respectivamente. O acompanhamento mensal tem o maior número para o Neuropediatra $(43,9 \%)$ e Assistente Social $(31,71 \%)$, já o Psicólogo não é frequentado por $75,6 \%$. De acordo com outro estudo, a criança com microcefalia deve ser atendida por uma equipe de saúde interdisciplinar constituída por, no mínimo, assistente social, fisioterapeuta, fonoaudiólogo, médico, odontólogo, psicólogo e terapeuta ocupacional, entendendo assim a importância de orientar aos pais quanto a atuação de cada profissional no crescimento dessas crianças com sequela neurológica e traçar um perfil de interesse maior sobre o desenvolvimento cognitivo, motor e independência desses lactentes $^{17}$ (Gráfico 2). 
Gráfico 2. Frequência de acompanhamento multiprofissional ( $n=41)$, em Salvador e região metropolitana.

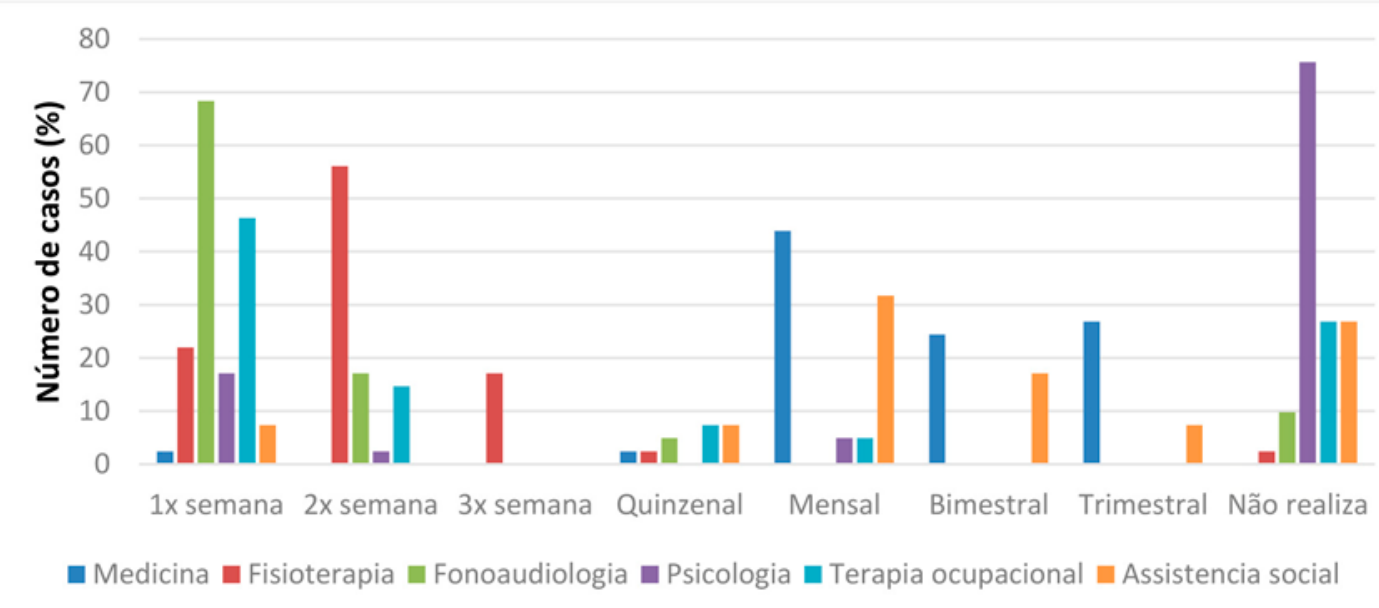

Fonte: Elaborado pelas autoras, 2017.

\section{Considerações finais}

Verificou-se que a maioria dos genitores entrevistados estão sem emprego e isso se deve muitas vezes ao abandono de suas atividades remuneradas para suprir a necessidade dos cuidados do seu bebê com necessidades especiais. Apesar de parte da população estudada possuir condições sanitárias inadequadas como coleta de lixo irregular e esgoto ao céu aberto próximo de suas residências, o maior número afirma possuir essas condições.

Baseando-se nesses resultados foi observado que há uma frequência predominante de genitores que dispõem de crianças com microcefalia relacionada ao Zika Vírus em baixas condições socioeconômi$\mathrm{ca}$, que consequentemente não conseguem suprir a maioria das necessidades que um lactente com má formação necessita.

Propõe-se que as politicas públicas orientem de forma mais severa a educação dessa população de condição socioeconomicamente baixa, já que o problema da maioria não se refere a condições sanitárias, como por exemplo: alertando sobre o uso de calças e blusas compridas durante o período gestacional, a importância do uso de repelente várias vezes ao dia, evitar viagens para locais com grandes evidências de epidemia do vírus Zika, além da conscientização sobre planejamento familiar.
Considera-se necessário a realização de novos estudos para conhecer essas famílias em todas as suas necessidades com o passar dos anos e identificar novas necessidades da população vítima dessa epidemia do vírus Zika.

\section{Contribuições das autoras}

Gonçalves AE e Tenório SDB contribuíram na pesquisa para desenvolvimento da introdução, resumo, escreveram o manuscrito, elaboraram o questionário e $\circ$ Termo de Consentimento Livre e Esclarecido. Levaram o projeto da pesquisa para a coordenadora do espaço onde seria realizado as entrevista. Foram para campo coletar os dados e após análise dos resultados realizada pela estatística desenvolveram resultados e discussão. As considerações finais foi elaborada pelas duas e autorizada pela pesquisadora responsável. A autora Ferraz PCS contribuiu nas orientações de cada etapa da pesquisa, corrigindo e acrescentando no que era necessário, indicou - local para coleta de dados e fez a intermediação para iniciar-se a pesquisa.

\section{Conflitos de interesses}

Nenhum conflito financeiro, legal ou político envolvendo terceiros (governo, empresas e fundações privadas, etc.) foi declarado para nenhum aspecto do trabalho submetido (incluindo mas não limitandose a subvenções e financiamentos, conselho consultivo, desenho de estudo, preparação de manuscrito, análise estatística, etc). 


\section{Referências}

1. Ministério da Saúde. Tira-dúvidas Dengue, Chikungunya e Zika [Internet]. [acesso em: 2016 mai. 28]. Disponível em: http://combateaedes.saude.gov.br/index.php/tiraduvidas\#chikungunya

2. Henriques CMP, Duarte E, Garcia LP. Desafios para o enfrentamento da epidemia de microcefalia. Epidemiol Serv Saúde. 2016;25(1):7-10. doi: 10.5123/s167949742016000100001

3. Secretaria da Saúde. Boletim de Microcefalia [Internet]. [acesso em 2016 mai. 25]. Disponível em: http://www.saude. ba.gov.br/novoportal/index.php?option=com_content\&view= article\&id= 10457:boletim-de-microcefalia\&catid=13:noticia s\&ltemid $=25$

4. Peñas JJG, Andújar FR. Alteraciones del perímetro craneal: microcefalia y macrocefalia. Pediatra Integral. 2007; $\mathrm{XI}(8): 701-716$.

5. Sá LMSMP. Intervenção Precoce e Microcefalia: Estratégias de Intervenção Eficazes. [dissertação]. Lisboa: Escola Superior de Educação João de Deus; 2013.

6. Barton MA, Salvadori MI. Zika virus and microcephaly. CMAJ. 2016;188(7):E1 18-9. doi: 10.1503/cmaj.160179

7. Adibi JJ, Marques ETA, Cartus A, Beigi RH. Teratogenic effects of the Zika virus and the role of the placenta. Rev. Lancet. 2016;387(10027):1587-1590. doi: 10.1016/ s0140-6736(16)00650-4

8. Buss PM, Pellegrini Filho A. A Saúde e seus Determinantes Sociais. Physis. 2007;17(1):77-93. doi:10.1590/S010373312007000100006

9. Marinho F, Araújo VEM, Porto DL, Ferreira HL, Coelho MRS, Lecca RCR et al. Microcefalia no Brasil: prevalência e caracterização dos casos a partir do Sistema de Informações sobre Nascidos Vivos (Sinasc), 2000-2015. Epidemiol Serv Saúde. 2016;25(4):701-712. doi: 10.5123/s167949742016000400004

10. Vargas A, Saad E, Dimech GS, Santos RH, Sivini MAVC, Albuquerque $\mathrm{LC}$ et al. Características dos primeiros casos de microcefalia possivelmente relacionados ao vírus Zika notificados na Região Metropolitana de Recife, Pernambuco. Epidemiol Serv Saúde. 2016;25(4):691-700. doi: 10.5123/ s1679-49742016000400003

11. Xavier CL, Brito JNPO, Moura MEB, Abreu BAL, Brito ES. Condições de saúde da criança acometida por paralisia cerebral na Estratégia Saúde da Família. Rev Cuidado e Fundamental. 2014;6(5):22-23. doi: 10.9789/2175$\underline{5361.2014 . v 6 i 5.22-33}$
12. Maguiña $C$, Galán-Rodas E. El virus Zika: una revisión de literatura. Acta méd peruana. 2016;33(1):35-41.

13. Alves LV, Cruz DCS, Linden AMC, Falbo AR, Mello MJG, Paredes CE et al. Crises epilépticas em crianças com síndrome congênita do Zika vírus. Rev Bras Saude Mater Infant. 2016;16(supl 1):S33-S37. doi: 10.1590/18069304201600s100003

14. Salge AKM, Castral TC, Sousa MC, Souza RRG, Minamisava R, Souza SMB. Infecção pelo vírus Zika na gestação e microcefalia em recém-nascidos: revisão integrativa de literatura. Rev Eletr Enf. 2016;18:e 11 150. doi: $10.5216 /$ ree.v18.39888

15. Abreu TT, Novais MCM, Guimarães ICB. Crianças com microcefalia associada a infecção congênita pelo vírus Zika: características clínicas e epidemiológicas num hospital terciário. Rev Ciênc Méd Biol. 2016;15(3):426-433. doi: $10.9771 / \mathrm{cmbio.v15i3.18347}$

16. Vernier ETN, Cabral IE. Caracterização de crianças com necessidades especiais de saúde e seus familiares cuidadores. Santa Maria (RS). 2004-2005 subsídios para intervenções de enfermagem. Rev Soc Bras Enferm Ped. 2006;6(1):37-45.

17. Norbert AAF, Ceolin T, Christo V, Strassburger SZ, Bonamigo ECB. A importância da estimulação precoce na microcefalia. In: XXIV Seminário de Iniciação Científica. 2016; ljuí. ljuí: Unijui; 2016.

18. Ministério da Saúde. Protocolo de atenção à saúde e resposta à ocorrência de microcefalia relacionada à infecção pelo vírus Zika. Brasília: Ministério da Saúde; 2016.

19. Dantas MSA, Pontes JF, Assis WD, Collet N. Facilidades e dificuldades da família no cuidado à criança com paralisia cerebral. Rev Gaúcha Enferm. 2012;33(3):73-80. doi: $10.1590 /$ S1983-14472012000300010

20. Cardoso AMR, Felipe ACM, Nunes FMR, Padilha WWN. Programa de Saúde Bucal Domiciliar para Crianças e Adolescentes com Paralisia Cerebral. Pesq Bras Odontoped Clin Integr. 2012;1 2(1):1 27-33. doi: 10.4034/ PBOCl.2012.121.20

21. Salvador MS. Vivências do familiar no cuidado a crianças com doenças crônicas: subsídios para a prática da enfermagem [dissertação]. Rio grande: Universidade Federal do Rio Grande; 2013.

22. Almeida MI, Molina RCM, Vieira TMM, Higarashi $\mathrm{IH}$, Marcon SS. O ser mãe de criança com doença crônica: realizando cuidados complexos. Esc Anna Nery R Enferm. 2006;10(1):36-46. doi: 10.1590/S141481452006000100005 
23. Junior MC. Microcefalia e o Benefício de Prestação Continuada-BPC [Internet]. 2016 [acesso em 2016

ago]. Disponível em: https://jus.com.br/artigos/51607/ microcefalia-e-o-beneficio-de-prestacao-continuada-bpc

24. IOB. Garantidos benefício á criança com microcefalia e licença-maternidade á mãe de criança com sequelas causadas pelo Aedes aegypti [Internet]. 2016 [acesso em 2017 jun. 09]. Disponível em: http://www.seteco.com.br/ garantidos-beneficio-crianca-com-microcefalia-e-licencamaternidade-mae-de-crianca-com-sequelas-causadas-peloaedes-aegypti/

25. Reis RP. Surto de microcefalia no Brasil. Rev Min Enferm. 2015;19(4):809-814. doi: 10.5935/1415-2762.20150061 